\title{
SOCIEDADE, NATUREZA E TEMPO: DISPUTA DE RACIONALIDADES
}

\author{
Felipe Bueno Amara* ${ }^{*}$ \\ José Luiz Fernandes Cerveira Filho**
}

\begin{abstract}
Resumo
O presente artigo discorre sobre a visão herdada (ou, poderíamos dizer, construída) da sociedade contemporânea, que vê o ambiente natural como propriedade. No entanto, o estudo mostra que o processo para se chegar até essa visão passou do afastamento homem/natureza para um posterior domínio, uma sobreposição do homem ao ambiente natural, por vezes denominado no texto como "natureza". O objetivo do texto é analisar de modo distanciado de um pano de fundo específico essa inter-relação, verificando e ressaltando a sua forma sem, no entanto, determinar de modo explícito as razões das quais decorrem os problemas ambientais advindos dela e sem ressaltar os impactos negativos, uma vez que o propósito é tão somente a análise da relação e não suas consequências. Percebeu-se, no decorrer do trabalho, que a relação de sobreposição advém de um processo histórico/cultural, que culmina nos atuais problemas ambientais. $\mathrm{O}$ estudo identifica a necessidade de ampliar as margens da visão epistêmica cartesiana (indivíduo/objeto conhecido) e enfatiza a necessidade de uma relação de compreensão e de diálogo para com o ambiente natural, devido à importância dele para todas as sociedades, inclusive a humana.
\end{abstract}

Palavras-chave: Sociedade. Natureza. Racionalidade.

* Graduado em Tecnologia em Gestão Ambiental pela UNOESC, mestrando em Sociologia pela UFPR, pesquisador colaborador do Centro de Estudos Rurais e Socioambientais do Paraná, CERU/PR. Email: felipebamaral@ hotmail.com.

** Doutor em Tecnologia, Ambiente e Sociedade pela UFSCAR, mestre em Sociologia Política pela UFSC, professor do Programa de Pós-Graduação em Sociologia e Programa de Pós-Graduação em Meio Ambiente e Desenvolvimento da UFPR.Email: j_cerveira@ufpr.br. 


\section{Introdução}

Se sou mais que uma pedra ou uma planta? Não sei. Sou diferente. Não sei o que é mais ou menos.

(Fernando Pessoa)

Nos dias atuais, percebe-se um aumento da atenção dos mais variados campos da sociedade à questão ambiental. A proposta deste trabalho é rastrear a partir disso, de modo generalista, o caminho traçado pela inter-relação entre a sociedade e a natureza.

Não se pretende chegar dialeticamente, neste breve estudo, numa perspectiva maniqueísta, e sim ao esclarecimento acerca de onde adquirimos o conhecimento do meio ambiente e como interagimos como seres humanos com tal meio. A proposta é ilustrar as origens da denominada cultura de dominação do homem sobre o meio natural e como isso se desenvolve nas diferentes sociedades, sem adentrar na questão da gestão ambiental de avaliação e mitigação de impactos positivos ou negativos.

Essa discussão entre ambientalistas e cientistas, entre sociedade urbana e sociedade rural é que originou a busca do conhecimento pela inter-relação destas sociedades com a natureza, uma vez que a própria natureza está dentro da cultura das sociedades e vice-versa. Rappaport (1982, p. 260) argumenta que "[...] o estudo da ecologia humana não pode ignorar fenômenos tais como guerra, convenção matrimonial, organização política ou, mesmo, religião." Devido a essas variações culturais, as racionalidades em disputa e sua complexidade, o autor admite a dificuldade de uma análise precisa, um apontamento exato em direção ao real, que engendra em si a dinâmica da complexidade.

Não se pretende aqui fragmentar todas as formas de relação do homem com o meio ambiente, mas se procura apontar um caminho para tais análises. Veremos mais adiante, em Benedict (1982), que a cultura, ou sua transformação, ocorre em um processo lento e laborioso; então, a partir dessa concepção, buscou-se analisar a origem da relação homem/natureza e como se desenvolveu tal relacionamento.

A evolução histórica do conhecimento esclareceu que uma análise epistêmica, indivíduo/objeto, não consegue responder às questões dessa relação, tampouco seus caminhos. "[...] A natureza é vista pelos homens através de uma tela composta de crenças, conhecimentos e intenções, e os homens agem a partir de suas 
imagens culturais da natureza, e não a partir da estrutura real da natureza." (RAPPAPORT, 1982, p. 261).

Defende-se, a partir disso, um olhar com desvelo para essa relação, e uma aceitação dos variados modos de ser das sociedades e seus rituais nos permitirá um agir com compreensão, em busca de um saudável relacionamento com o natural, sem um padrão pré-estabelecido.

\section{Da relação homem-natureza}

O homem, segundo Rappaport (1982), na sua condição de animal está indissoluvelmente ligado aos ambientes compostos por outros organismos e substâncias não vivas, de que depende para retirar matéria e energia para se sustentar, e em razão disso precisa se adaptar para não perecer. A forma como a sociedade ocidental contemporânea se relaciona com o ambiente natural é decorrente de um processo histórico de dominação e posse antropocêntrica sobre a ecosfera. Observa-se isso em Gonçalves (1989, p. 28): "[...] a separação homem-natureza (cultura-natureza, histórianatureza) é uma característica marcante do pensamento que tem dominado o chamado mundo ocidental, cuja matriz filosófica se encontra na Grécia e Roma clássicas”.

Vamos perceber uma nesga da herança dessa matriz também no racionalismo de René Descartes (1978, p. 113-114) em seu Discurso sobre o método:

[...] é possível chegar a conhecimentos que são muito úteis para a vida e que, em vez dessa filosofia especulativa que se ensina nas escolas, pode-se encontrar numa outra prática pela qual conhecendo a força e a ação do fogo, da água, do ar, dos astros, dos céus e de todos os outros corpos que nos cercam tão distintamente como conhecemos os diversos misteres de nossos ofícios poderíamos empregá-los da mesma maneira em todos os usos para os quais são próprios e assim nos tornar como que senhores e possuidores da natureza.

Para Benedict (1982, p. 243), o “[...] desenvolvimento cultural tem sido [...] uma espécie de laboriosa construção de um casulo, cada vez mais complexo. Mas os fios deste casulo são ainda hábitos antigos, selecionados e simples, mesmo quando trabalhados sob formas de complicadas práticas [...]”. 
Por isso, supõe-se, a sociedade atual não percebe tal dominação através do desenvolvimento da cultura, e, de um modo geral, sequer atenta para a necessidade dessa inter-relação. Isso acontece através de um discurso que perpassa a fronteira do tempo e se mantém estável na formação social dos indivíduos. Lembramos que discurso é "um modo de construir sentidos que influencia e organiza tanto nossas ações quanto a concepção que temos de nós mesmos" (HALL, 2000, p. 50).

Lovelock (2006, p. 130) explica que "[...] esta falsa crença de que somos donos da terra, ou seus dirigentes permitem que nos declaremos a favor das políticas e programas ambientais, mas continuemos deixando as coisas como estão [...]”. Para o autor, a humanidade, bombardeada pelos meios de comunicação, concorda com a necessidade de um desenvolvimento sustentável, por exemplo, mas não consegue mudar os hábitos pré-estabelecidos.

Uma olhada em qualquer jornal financeiro confirma que nosso objetivo ainda é o crescimento e o desenvolvimento. Vibramos com qualquer descoberta de depósitos de gás ou petróleo e consideramos o aumento atual dos preços de petróleo um desastre potencial, ou a iminência do desastre global catastrófico. A compreensão se limita à mente consciente, não despertando uma reação visceral de medo. (LOVELOCK, 2006, p. 130).

Essa visão de mudança, esse desvelo antropocêntrico para com o meio natural, deveria advir, segundo Lovelock (2006, p. 130), de uma "sensação intuitiva, um instinto, que diga quando é que Gaia corre perigo”. Entretanto, como indivíduos inseridos na sociedade midiática, pouco temos de intuição ao natural, em virtude da mínima ou nenhuma disseminação de tal cultura. Ao contrário, julgamos pejorativa toda imagem natural, tolhendo o instinto, as pulsões e as paixões (GONÇALVES, 1989).

A herança dominadora do homem se perpetua, provocando graves consequências ao meio biótico. Com relação à organização tradicional das sociedades, Gonçalves (1989, p. 26) enfatiza que "Na verdade, encontramo-nos diante de um conceito de natureza que justifica a existência do Estado. Este é condição de 'civilização' e 'primitivos' são os povos que não têm Estado.” Aqui Gonçalves (1989) deixa explícita a forma pela qual a sociedade foi arregimentada - um extermínio das coisas naturais, um afastamento. 
E esse afastamento é simbolizado pela cultura do ocidente, que rotula o selvagem como atrasado, alheio aos costumes contemporâneos. De certo modo, podemos perceber essa estranheza na relação homem urbano/homem rural, em que este recebe o estigma de poluidor do ambiente natural e é subjugado por aquele em vários sentidos, estabelecendo uma relação "monopsônica" (PESAVENTO, 1983 apud BROSE, 2000, p. 35).

Consideramos de modo perspectivista que um relativo "domínio" da natureza, no entanto, é natural e é o que torna "possível a nossa sobrevivência" (GADAMER, 2000). Indubitável é, pois, que o homem, após toda a evolução decorrente do processo de seleção natural, tenha aprendido a melhor forma de adaptação ao meio, e isso implicou uma sobreposição. No entanto, para Rappaport (1982, p. 258), “Todas as criaturas, inclusive os homens, devem manter o tamanho da sua população dentro dos limites da capacidade que seus ambientes têm de sustentá-los." Conclui-se, assim, que à medida que ocorre um crescimento antropocêntrico e a ciência revela seus malefícios, mesmo com os erros de previsão da teoria malthusiana, a incorreta interpretação daquilo que Nietzsche (2007) chamou de "vontade de potência" impede um abrir de olhos para o campo natural de onde advém nossa subsistência, nosso ser, e onde se constroem contextualmente diversas racionalidades.

Uma nova racionalidade se mostra substantiva para equilibrar os limites de um racionalismo. Emprestamos novamente as palavras de Ruth Benedict (1982, p. 235), que observa: "desenvolvimento e destruição andam lado a lado. A cultura, da mesma forma que cresce, também destrói, e ao destruir determina novo desenvolvimento".

[...] o homem contemporâneo tornou-se uma engrenagem da imensa máquina burocrática, alienado, manipulado pela indústria, pelos mass media, pelos governos, exposto a perigos ecológicos e ao risco de conflitos nucleares, psicologicamente deprimido, isolado, angustiado, presa de impulsos destrutivos [...] (TIEZZI, 1988, p. 189).

Este estudo não visa à defesa ecológica do ambiente natural e nem pretende analisar os impactos causados pela atividade antropocêntrica. Contudo, é necessário ressaltar o oximoro de um desenvolvimento que pretende ser sustentável, sem, no entanto, 
estabelecer limites de crescimento (demográfico, de desperdício de energia, da poluição, etc.).

Assim Tiezzi (1988, p. 172) salienta: "Colocar limites ao crescimento significa garantir a sobrevivência da espécie humana e negar a sociedade consumista. Não há nada de reacionário nisso." Negar a sociedade de consumo pode ser um passo para o desenvolvimento humano. Para Leis (1999, p. 162-163),

Os problemas ecológicos e as demandas de sustentabilidade levam a concluir que as metas prioritárias da ciência deixaram de ser a conquista da natureza [...]. Na investigação de problemas socioambientais complexos, mais que a procura de fundamentos epistemológicos ou de conhecimentos básicos comuns, interessa encontrar os valores comuns que permitam a convergência das diferentes abordagens disciplinares entre si e com as posições do público leigo. É neste sentido que a passagem da conquista da natureza para uma relação mais "amorosa" supõe uma ruptura epistemológica.

Esse irromper com os preceitos, para Gadamer (2000, p. 23), é um abandono do objeto conhecido, para uma relação de redescoberta que aproxima e liberta. "A natureza é, também, tal dado, que não se pode resguardar apenas através do medir e do calcular, mas algo com o qual e no qual se tem de aprender a viver, de tal modo que se respire mais livremente." Para tanto, Morin (2002, p. 156) ressalta a ideia de quebra das relações com uma visão epistêmica cartesiana: "O objeto não é mais uma formaessência e/ou matéria substância. Não há mais forma-molde que esculpa a identidade do objeto do exterior. A ideia de forma é conservada, mas transformada [...]".

Essa mudança de pensamento, entretanto, não é simples, segundo o autor. $\mathrm{O}$ método de renegar, de todo conhecimento cartesiano é, para ele, incerto. "Descartes podia, ao mesmo tempo, em seu discurso primeiro, exercer a dúvida, exorcizar a dúvida [...]. A dúvida cartesiana tinha confiança em si. A nossa dúvida duvida de si mesma; ela descobre a impossibilidade de ignorar o que já é sabido [...]" (MORIN, 2002, p. 29). Parece-nos que sustentar a visão de desenvolvimento através da noção epistêmica sujeito/objeto não abarca toda a complexidade que o eterno devir traz em si - tanto pela não diferenciação do modo de ser e das relações sujeito/objeto quanto pela lenta mudança de costumes e hábitos de pensamento sociais. 
A estratégia que nos é sugerida pela perspectiva ecológica, portanto, é a de considerar o homem como uma espécie cujas populações vivem entre outras espécies, para melhor compreender o que distingue, mas não o separa, do resto da natureza, e para melhor compreender o que distingue os grupos de homens uns dos outros [...]. (RAPPAPORT, 1982, p. 259).

E é nesse sentimento de compreensão e relação que Taylor (2000, p. 16) rompe com a visão cartesiana, epistêmica de objeto conhecido. "[...] a certeza é algo que a mente tem de gerar por si mesma. Exige uma virada reflexiva em que, em vez de simplesmente confiar nas opiniões que se adquiriu ao longo da criação, examinam-se o fundamento destas, que deve ser encontrado em última análise em nossa própria mente [...]”.

Em última consequência, romper com o já conhecido sugere impossibilidade, mas também necessidade de transmutação; por isso, Morin (2002) fala que a ideia de forma é conservada, mas transformada. É preciso romper com a crença antiga, transformando paulatinamente o entendimento, até que esse nos leve a uma compreensão do objeto, da forma que molda. Assim, compreender que "[...] a forma é a totalidade da unidade complexa organizada que se manifesta fenomenalmente enquanto todo no tempo e no espaço [...]". (MORIN, 2002, p. 156). E considerar que a multiplicidade das disputas das racionalidades talvez precise se reconhecer em unicidade para com o mundo, racionalizando as ações alinhadas com a proposição de Tiezzi (1988), que ressalta que os tempos históricos não condizem com os tempos biológicos.

\section{Considerações finais}

Nossa discussão se concentrou de modo generalizante em como a sociedade construiu a relação com a natureza, razão pela qual se torna emergente o despertar de uma racionalidade substantiva que contemple a noção de complexidade e que permita o processo de desenvolvimento da multiplicidade. Dito de outro modo, parece-nos necessário desvelar a relação com o mundo que nos produz ao mesmo tempo em que é produzido por nós.

A relação de apropriação e controle da sociedade humana para com o ambiente natural permitiu que decorressem problemas ambientais e sociais (como nos casos de fome e falta de água potável, por exemplo), gerados pelo não reconhecimento da importância do meio natural para as sociedades, ou seja, gerado 
pela forma das diversas sociedades. Este encobrimento do real dinâmico que perpassa as gerações pode decorrer da não percepção das diferenças entre os tempos econômicos, biológicos e culturais.

Esse obscurecimento permite que nossa cultura se transforme em um tempo mais lento que as transformações biológicas ou mesmo econômicas. É possível, pois, alterar a forma como vemos o ambiente natural, para ressignificarmos esse eterno relacionar?

\section{Referências}

BENEDICT, Ruth. O desenvolvimento da cultura. In: SHAPIRO, Harry L. (Org.). Homem, cultura e sociedade. São Paulo: Martins Fontes, 1982. cap. VIII. p. 235-249.

BROSE, Markus. Agricultura Familiar, desenvolvimento local e políticas públicas. Santa Cruz do Sul: EDUNISC, 2000. 347 p.

DECARTES, René. Discurso sobre o método. São Paulo: Hemus, $1978.136 \mathrm{p}$.

GADAMER, Hans-Georg. Verdade e método I: traços fundamentais de uma hermenêutica filosófica. 10. ed. Petrópolis, RJ: Vozes, 2000. 631 p.

GONÇALVES, Carlos Walter Porto. Os (des) caminhos do meio ambiente. São Paulo: Contexto, 1989.148 p.

HALL, Stuart. A identidade cultural na pós-modernidade. 4. ed. Rio de Janeiro: DP\&A, 2000. 102 p.

LEIS, Hector Ricardo. A modernidade insustentável: as críticas do ambientalismo à sociedade contemporânea. Petrópolis: Vozes; Santa Catarina: UFSC, 1999. $261 \mathrm{p}$.

LOVELOCK, James. A vingança de Gaia. Rio de Janeiro: Intrínseca, $2006.159 \mathrm{p}$.

MORIN, Edgar. O método 1: a natureza da natureza. Porto Alegre: Sulina, 2002. $480 \mathrm{p}$.

NIETZSCHE, Friedrich W. Humano, demasiado humano. São Paulo: Escala, 2007.304 p.

RAPPAPORT, Roy A. Natureza, cultura e antropologia ecológica. In: SHAPIRO, Harry L. (Org.). Homem, cultura e sociedade. São Paulo: Martins Fontes, 1982. cap. IX. p. 251-282. 
TAYLOR, Charles. Argumentos filosóficos. São Paulo: Loyola, 2000. $311 \mathrm{p}$.

TIEZZI, Enzo. Tempos históricos, tempos biológicos. A terra ou a morte: os problemas da nova ecologia. São Paulo: Nobel, 1988. p. 204.

\title{
SOCIETY, NATURE AND TIME: DISPUTE RATIONALITIES
}

\begin{abstract}
This article discusses the vision inherited (or we could say built) of contemporary society, which views the natural environment as property. However, the study shows that the process to reach that vision has clearance man / nature, for a subsequent domain, an overlap of man to the natural environment, sometimes referred to in the text as nature. The purpose of the paper is to analyze a distant backdrop of this specific interrelationship, checking and highlighting how this relationship without, however, determining explicitly the reasons giving rise to the same environmental problems arising from the impact and without stress negative, since it is solely for the purpose of the relationship and not consequences. It was realized in the course of the work the overlapping relationship stems from a historical / cultural, culminating in today's environmental problems. The study identifies the need to expand the margins of Cartesian epistemological view (person / object known) and emphasizes the need for a relationship of understanding and dialogue for the natural environment, because of its importance for all societies, including human.
\end{abstract}

Keywords: Society. Nature. Rationality. 
